\title{
The effect of group discussion on self-care behaviors among hypertensive patients referring to health care centers in Arak City
}

\author{
Alireza Jamshidi ${ }^{1}$, Nasrin Rozbahani ${ }^{2}$, Maryam nasirian ${ }^{3}$ \\ 1.MSc of Community Education in the Health System, student research committee, School of health, Isfahan university of \\ medical sciences, Isfahan, Iran.ORCID CD:0000-0003-0699-810x \\ 2.Assistant professor of Health education \& promotion, Department of Health Education, Faculty of Health, Arak University \\ of medical sciences, Arak, Iran. \\ 3. Assistant professor of epidemiology, Epidemiology and Biostatistics Department, Health School; and Infectious Diseases \\ and Tropical Medicine Research Center, Isfahan University of Medical Sciences, Isfahan, Iran,Tel:03137923161, Email: \\ Maryamnasirian17@gmal.com, ORCID CD:0000-0002-8365-3845
}

\begin{abstract}
Background and Aim: Besides drug regimen, modifying self-care behaviors is effective in controlling high-blood pressure. The purpose of this study was to investigate the effect of group discussion on self-care behaviors in the patients with hypertension.

Materials and Methods: In this semi-experimental study, 100 hypertensive patients were selected randomly from 10 health care centers in Arak in 2012. After obtaining informed consent and before intervention, self-care questionnaire was filled out by both groups and blood pressure was measured. Four educational sessions were held weekly for the intervention group, while only lectures were delivered for the control group. After three months, self-care questionnaire was completed and blood pressure was measured again. Using spss (V.21), data were analyzed by independent and paired t-test, chi square test and multivariate analysis.p $<0 / 05$ was considered significant.

Results: Self-care score in the intervention group was significantly higher than that in the control group $(\mathrm{p}<0.0001)$. The patients in the intervention group had significantly lower systolic and diastolic blood pressures compared to the control group $(p<0.0001)$.

Conclusion: It seems that group discussion training can be an effective way to improve selfcare behaviors in the hypertensive patients and results in a significant reduction in blood pressure of the patients. Further studies on the impact of other educational methods on the self-care behavior of the patients are recommended.
\end{abstract}

Keywords: Hypertension, Self-care, Education, Group discussion

\section{Received: April 23,2019 Accept: Sep 15,2019}

How to cite the article: Alireza Jamshidi, Nasrin Rozbahani, Maryam nasirian. The effect of group discussion on self-care behaviors among hypertensive patients referring to health care centers in Arak City. SJKU 2019; 24 (5): 58-68

Copyright (C) 2018 the Author (s). Published by Kurdistan University of Medical Sciences. This is an open access article distributed under the terms of the Creative Commons Attribution-Non Commercial License 4.0 (CCBYNC), where it is permissible to download, share, remix, transform, and buildup the work provided it is properly cited. The work cannot be used commercially without permission from the journal. 


\section{تأثير آموزش به روش بحث تروهى بر رفتار خود مر اقبتى بيماران مبتلا به فشارخون بالاه مراجعه كننده به پايكاههاى بهداشتى شهر اراك}

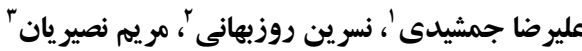

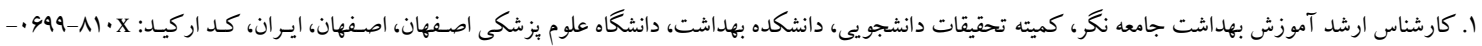

زمينه و هدف: در كنار رزيم دارويى، اصلاح رفتار خود مراقبى جهت كنترل بيمارى ير فشارى خون مؤثر است. هدف اين

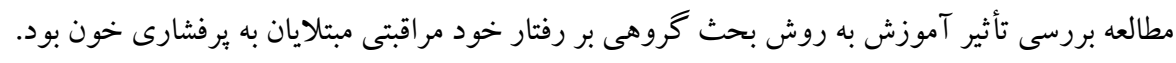

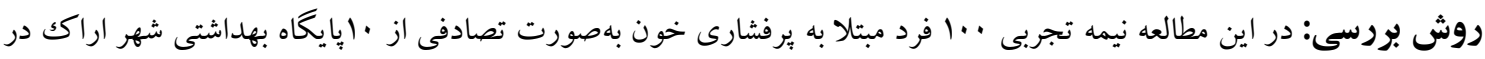

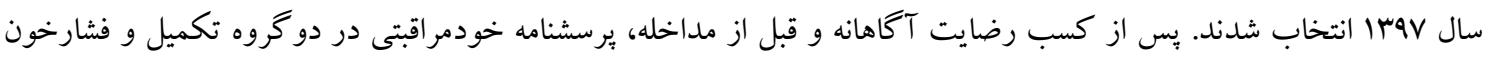

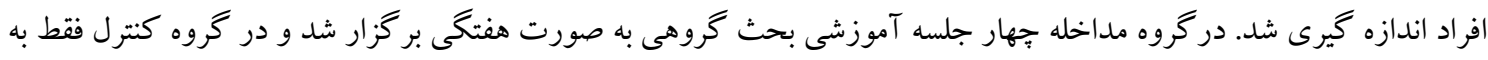

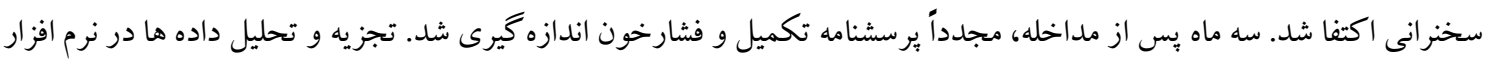

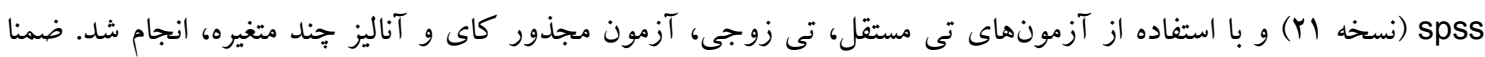
p منى دار تلقى گرديد.

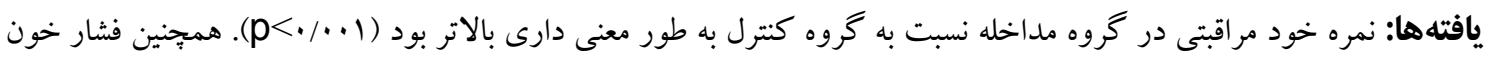

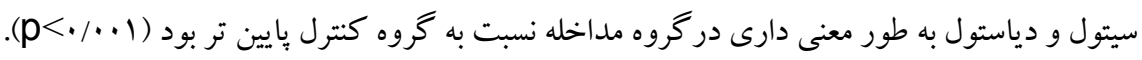

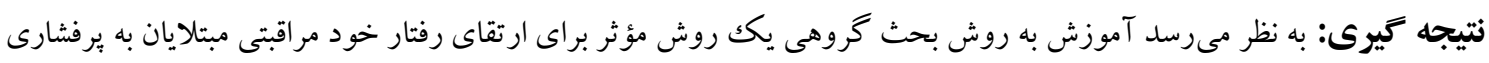

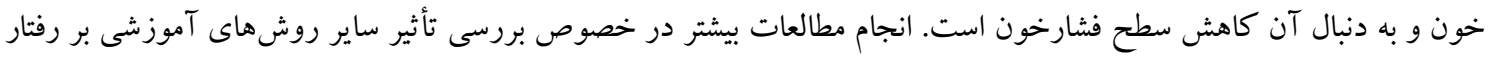
خود مر اقبتى بيماران بيشنهاد مى شود.

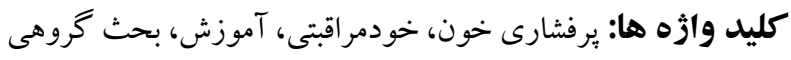
وصول مقاله: 
با توجه بـه اهميـت بيمـارى برفشـارى خـون بـه عنـوان يكك

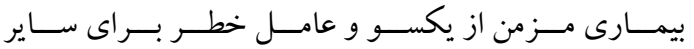

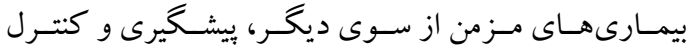

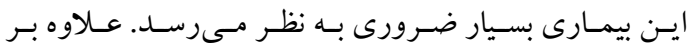

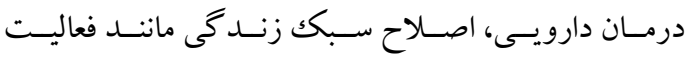

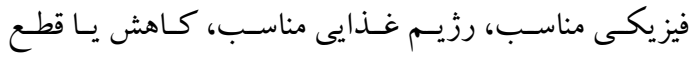

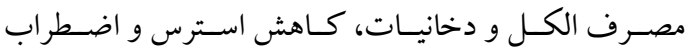

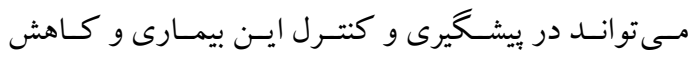

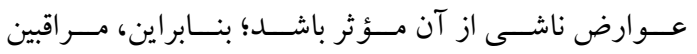

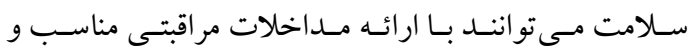

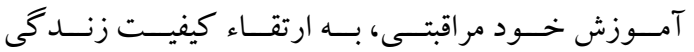

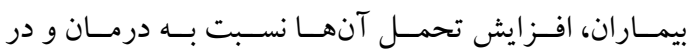

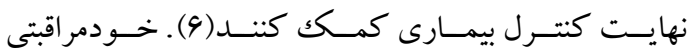

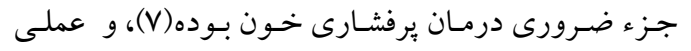

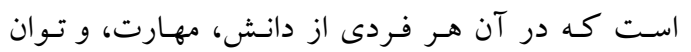

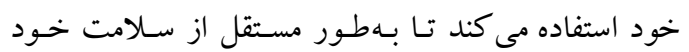

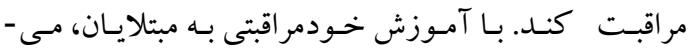

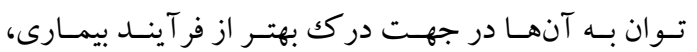

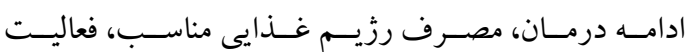
فيزيكى و مـديريت استرس و اضطراب كمـك كرد (A).

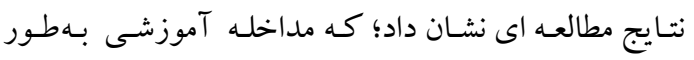

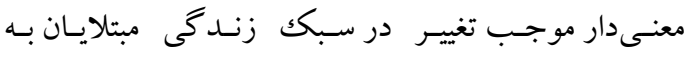

يرفشارى خون مى شود (9).

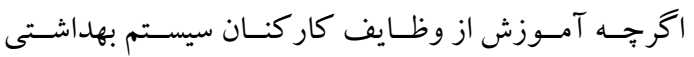

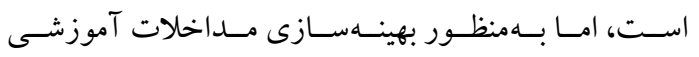

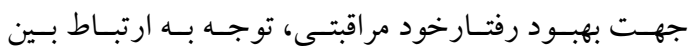

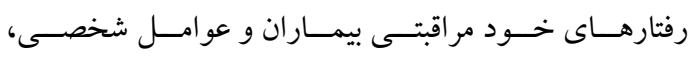

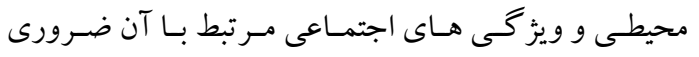

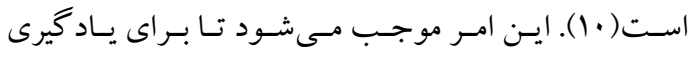

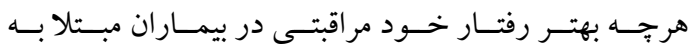

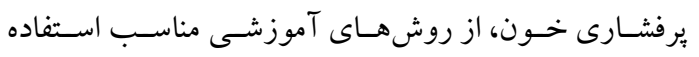
شـود. روشهــاى مختلفسى از جملـه سـخنرانى، برسـش و و

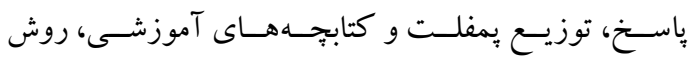

مقدمه

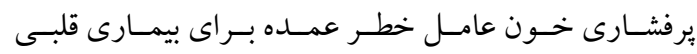
عروقسى، ايسـكمى، سـكته مغـزى همور ازيـكك و بيمـارى

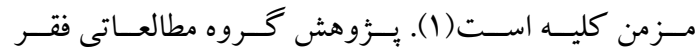

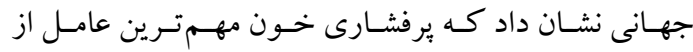

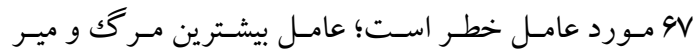

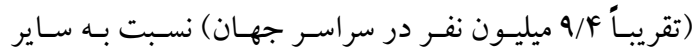

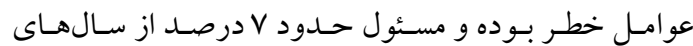

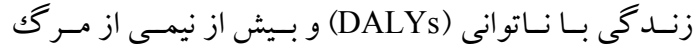
و ميـر ناشـى از بيمـارى ايسكميكك قلبى اســ(Y). ميـزان

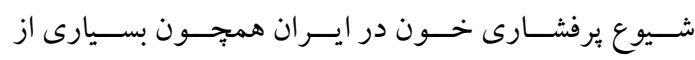

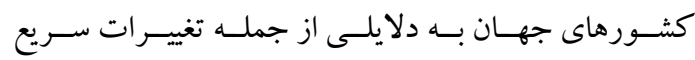

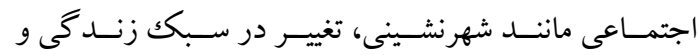

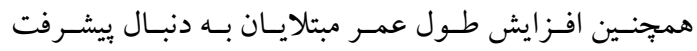

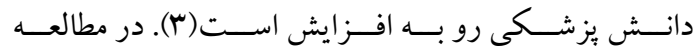

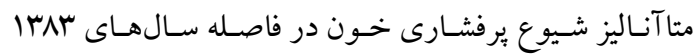

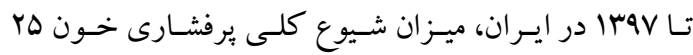

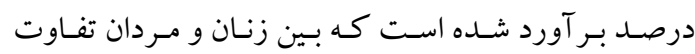

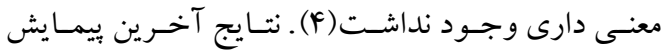

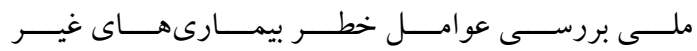

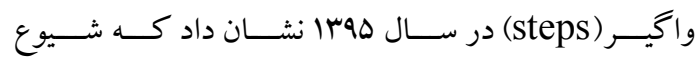

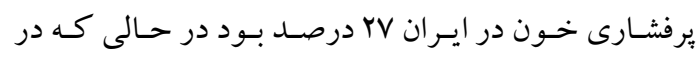

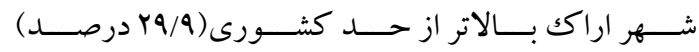

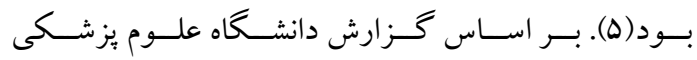

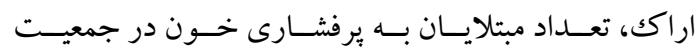

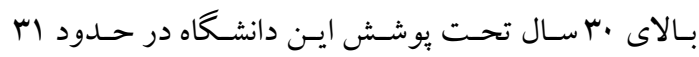

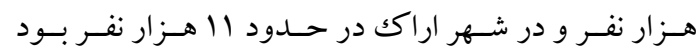

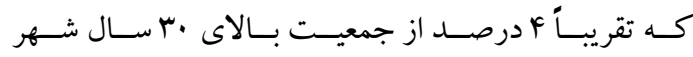

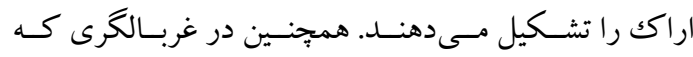

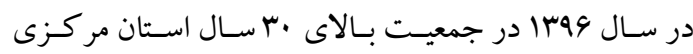

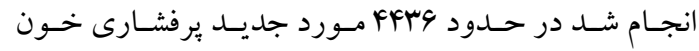

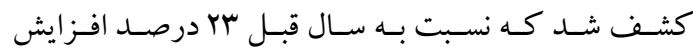

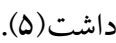




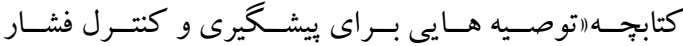

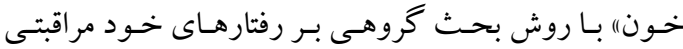

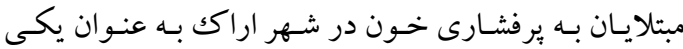

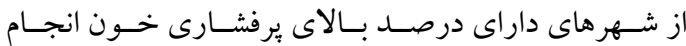

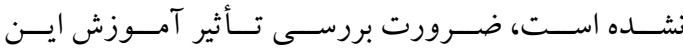

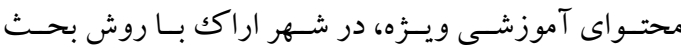
كروهـى در مقايسـهـ بـا روش جــارى ســنر انى بــر رفتـار

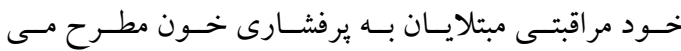

باشد.

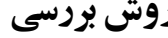

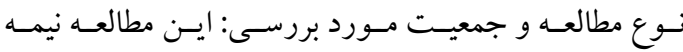

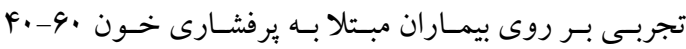

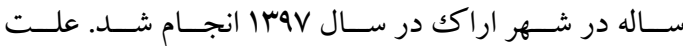

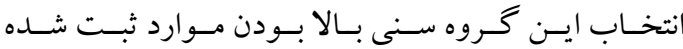
برفشـارى خـون در ايسن خـروه نسـبت بـه سـاير گـروههـاى سنى در مراكز بهداشتى شهر اراك است.

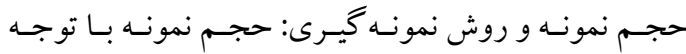
بـهـ مطالـهـ ايـزدى راد وهمكـاران(IV) و بـا در نظـر خـرفتن ادرصسد خطـاى نـوع اول و تـوان مطالعهـ •9 درصـد، در

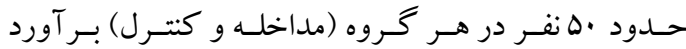

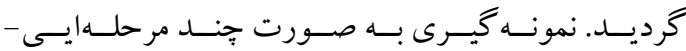
تصــادفى و در فاصـله ارديبهشـت مــاه تــا مردادمـاه سـال

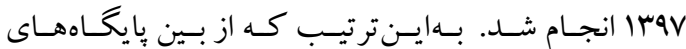

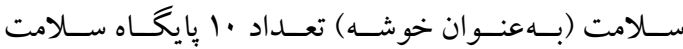

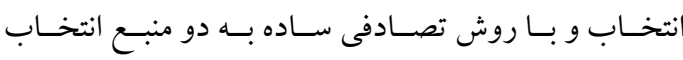

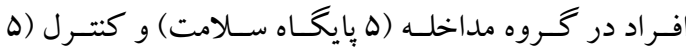

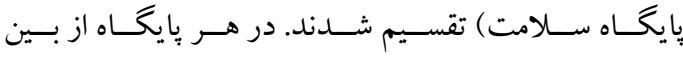

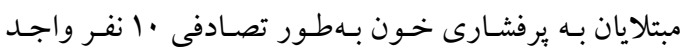

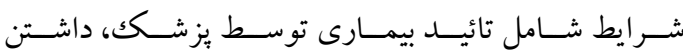

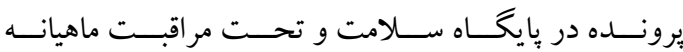

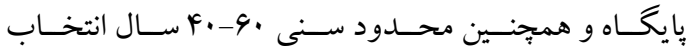

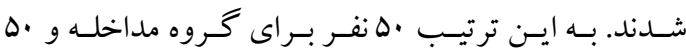

بحـث گروهى، بـراى آمـوزش رفتـار خـودمر اقبتى وجـود

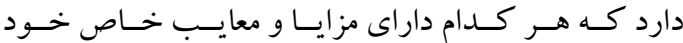
اسـت(1)؛؛ بـه عنـوان مثـال در روش سـخنرانى كـه از بيـان شـفاهى بــراى توضسيح و تفهـيم مطالـب استفاده مسىشـود،

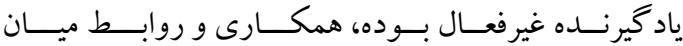

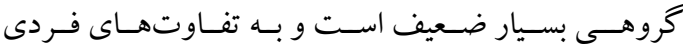

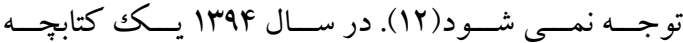
آموزشسى بــا نـام اتوصسيه هـايى بـــاى بيشــيرى و كنتـرل

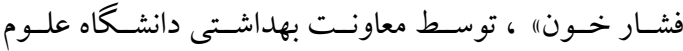

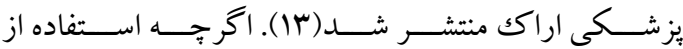

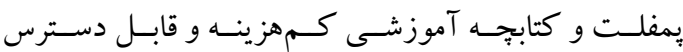

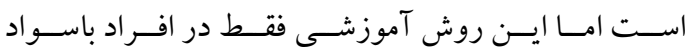
كـاربرد دارد و نسـبت بـهـ سـاير روشهــاى آموزشـى از

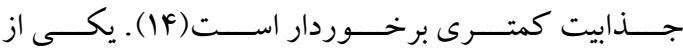

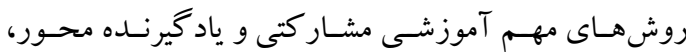

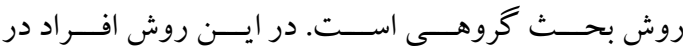
محيط دوستانه و راحت فرصت ييـدا مى كنتـد تـا نظرات

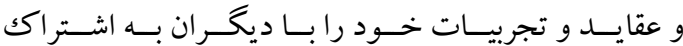
كذاشـته و فعالاتسه در امسر يــاد گيرى مشــار كت داشـته

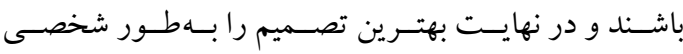

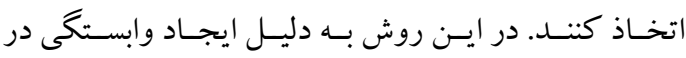

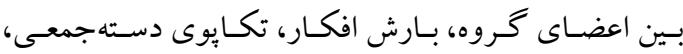

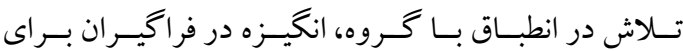

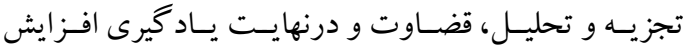

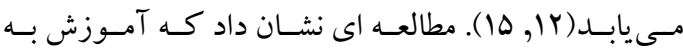

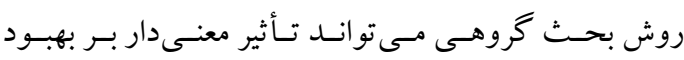

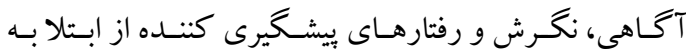

يرفشارى خون داشته باشد(19).

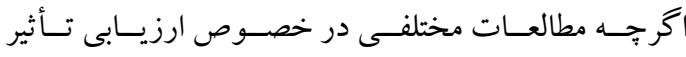

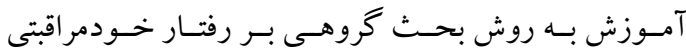

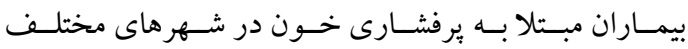

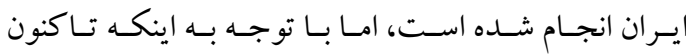

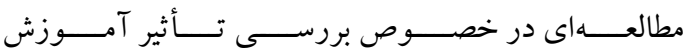


محتـو اى آموزشسى: محتـواى آموزشسى خـود مر اقبتى كـهـ منطبـق بــا سـؤوالات خــود مر اقبتـى در بر سشــنامه بــود، بــا

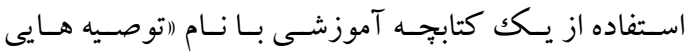
بـراى ييشـخيرى و كنتـرل فشـار خـون) كـه توسط معاونست

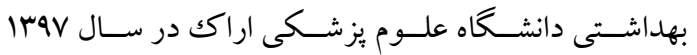

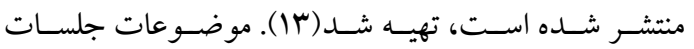

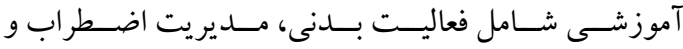
اســترس؛ تغذيــهـ ســـالم، كــاهش مصــرف دخانيــات و

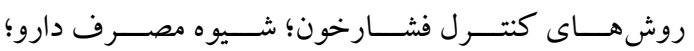

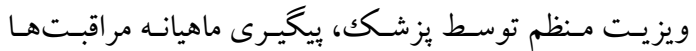

نحسوه مداخلـه: در هـر دو گحروه كنتـرل و مداخلـه جهــار جلسـه آموزشسى Y سـاعته بـه مـدت يـك مـاه (بـه صـورت مـنظم و هفتـهاى يـككبـار) بركـزار شـــ. جلسـات آموزشـى

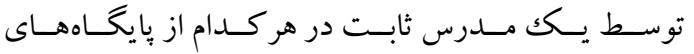
مداخله و كنترل بهصورت مجزا بر گزار شد.

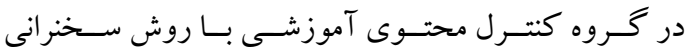

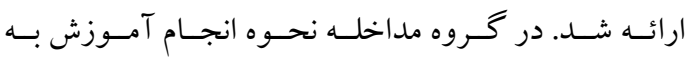

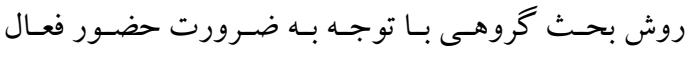
شـركت كنتـــان در يـاد گيرى، بـه ايـن ترتيـب بـود كـهـ در هــر جلسـهـ يـس از طـرح موضــوع توســ مــدرس و

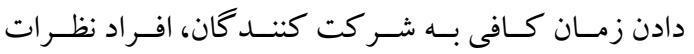

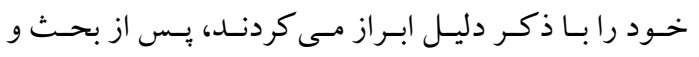
تبـادل نظـر همـه افـراد زيـر نظـر مــدرس، نتيجـه نهـايى بــا توجسه بـه بسـته آموزشسى توسط مـدرس جمـع بنــى مسى -

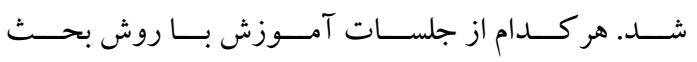

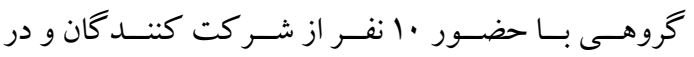
اتـاقى مخصـوص كـه نشسـتن افـراد بــه شـكل دايــره بـود اجرا شد تا تعاملات بين فردى به خوبى رعايت شود.

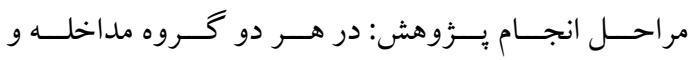

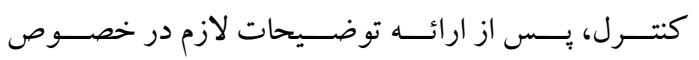

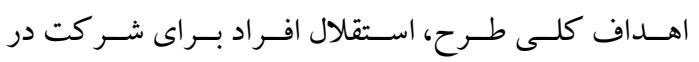
مطالعـه و محرمانـه مانـدن اطلاعـات، از شـركت كنـــــان
نفـر بـراى گحروه كنتـرل انتخـاب شـدند. معيارهـاى خـروج

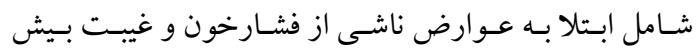
از يـكبـار در جلسـات آموزشـى بـود. لازم بـه ذكـر اسـت

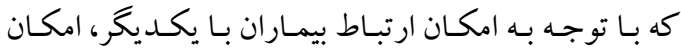
كورسازى آنها وجود نداشت. ابـزار جمــع آورى داده هــاو روايسى و يايــايى آنهـا: در

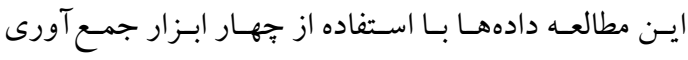

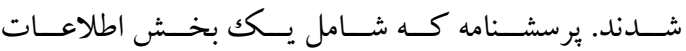

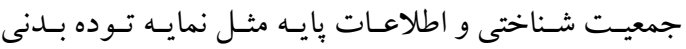
و ميـز ان فشــار خـــون ســـتوليكك و دياســتوليكك بيمــاران بــود. بخـش دوم يرسشــنامه كـه شــامل ·r ســؤال خــود

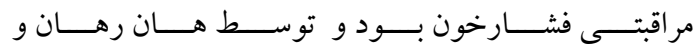

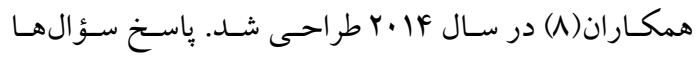

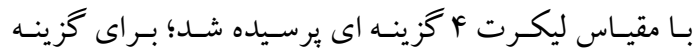

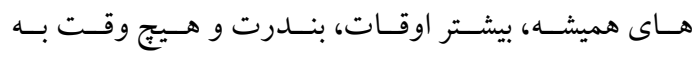

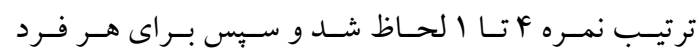

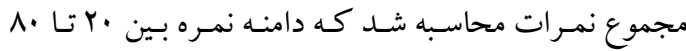
بـود و امتيـاز بـالاتر نشـان دهنـده رفتـار خـود مراقبتى بهتـر

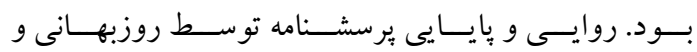

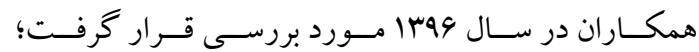

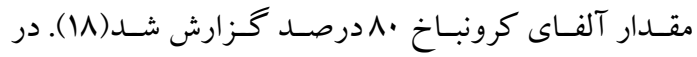
مطالعه حاضر مقدار آلفاى كرونباخ برابر با |N/ • بود.

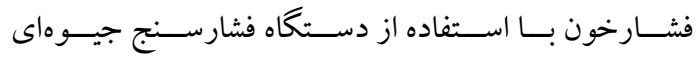
اسـتاندارد، قــــــــا اسـتفاده از قدســنج اسـتاندارد و وزن بــا

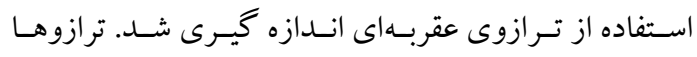

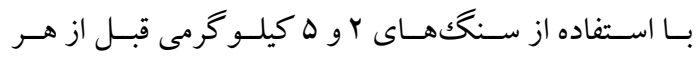

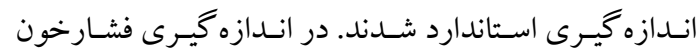

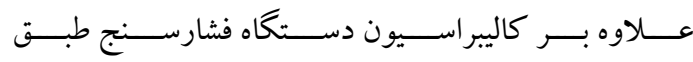

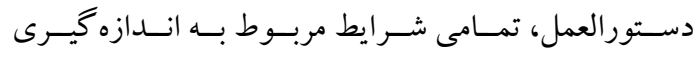

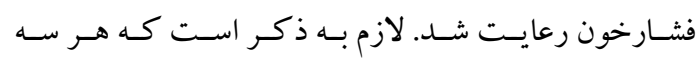

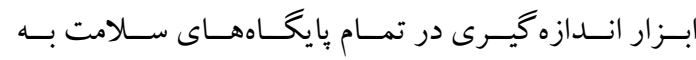
صورت متحدالشكل بودند. 
كروه كنترل و مداخله در قبل و بعد از مداخله از آزمون تى دو نمونه اي مستقل استفاده شد. با توجه به وجود جند بيامـد و همجنــن كنتـرل اثر متغيرهـاى مخـدوش كنتـده و كنتـرل تفاوت بين دو گروه در ابتداى مطالعه، از تحليل جنــ متغيـره استفاده شد. همجنين ه •/p معنى دار تلقى گرديد. لازم به يادآوريست؛ مطالعه توسط معاونت يُزوهشى دانشگاه

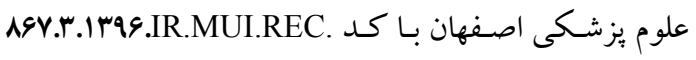
تصويب شد. همجنين قبل از اجراى مطالعه از كميتـه اخـلاق دانشـاه علـوم يزشـكى اراكك (محـل اجـراى طـرح) مجـوز دريافت شد.

يافته ها

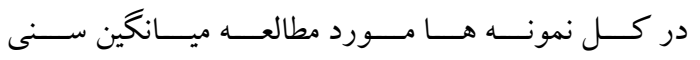
كــ/F

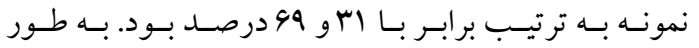

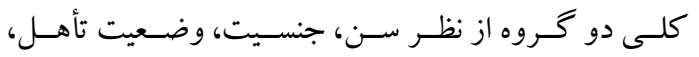

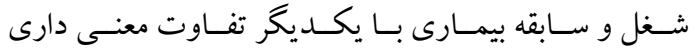
نداشـتند (ه • • > p) و همســان بودنــد. اكرجهـه دو گــروه از نظــر سـابقه بيمـارى بــا يكــديخر تفــاوت معنــى دارى

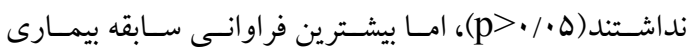
در هــر دو گـــروه مداخلــه و كنتـرل مربــوط بــه بيمـارى ديابـت بــود. دو خــروه مداخلـه و كنتـرل از نظــر سـابقه

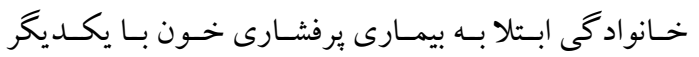

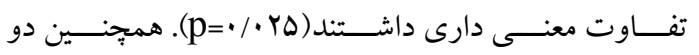
گــروه از نظـر تحصـيلات بــا يكـــيخر تفــاوت معنـى دار

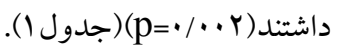

خواسـته شـد تــا فـرم رضـايت آكاهانسه را تكميـل كننـد. قبــل از مداخلــه، بــا رعايــت تمــام جوانــبـ اســاندارد،

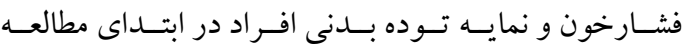

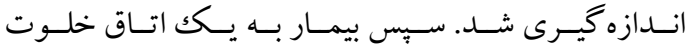

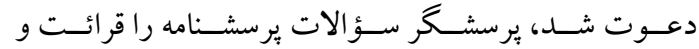

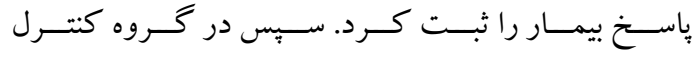

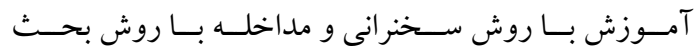
كروهى به مدت يكك ماه انجام شد.

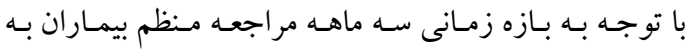
يزشك در برنامه خودمر اقبتى و همجنين زمانبـر بـودن تأثير

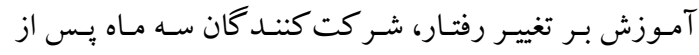
مداخله مورد ارزيابى مجدد قرار گرفتند به اين ترتيب كه در هر دو گرووه؛ مداخله و كنترل يرسشنامه خود مر اقبتى مجـدداً تكميــل شــــد و فشــارخون سيســتول و دياســتول و وزن شر كت كنند گان بهو سيله ابزار مشابه با مرحله قبل از مداخلـه، اندازه كيرى شد. تجزيه و تحليل داده ها: تجزيه و تحليل دادههـا در نـرم افزار (نسخه IY) SPSS شاخصهاى آمار توصيفى شـامل ميـانگين، انحر اف معيـار، فراوانى، درصد فراوانى استفاده شد. براى مقايسه مشخصـات دمو گر افيكك و ساير داده هاى بايه در گرووه مداخله و كنتـرل از آزمونهاى تى مستقل و آزمون مجذور كاى استفاده شـد. نمره خود مر اقبتى در سه سطح خوب (بالاى جـار كى سـوم)، متوسط (بين جار كك سوم و ميانه) و ضعيف (زير ميانه) دسته

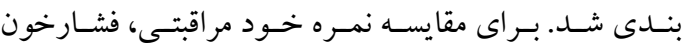
سسيستول و دياستول، وزن و نماى توده بلنى در قبـل و بعـــ از مداخله در هر كدام از گرووها از آزمون تسى زوجى و دو 


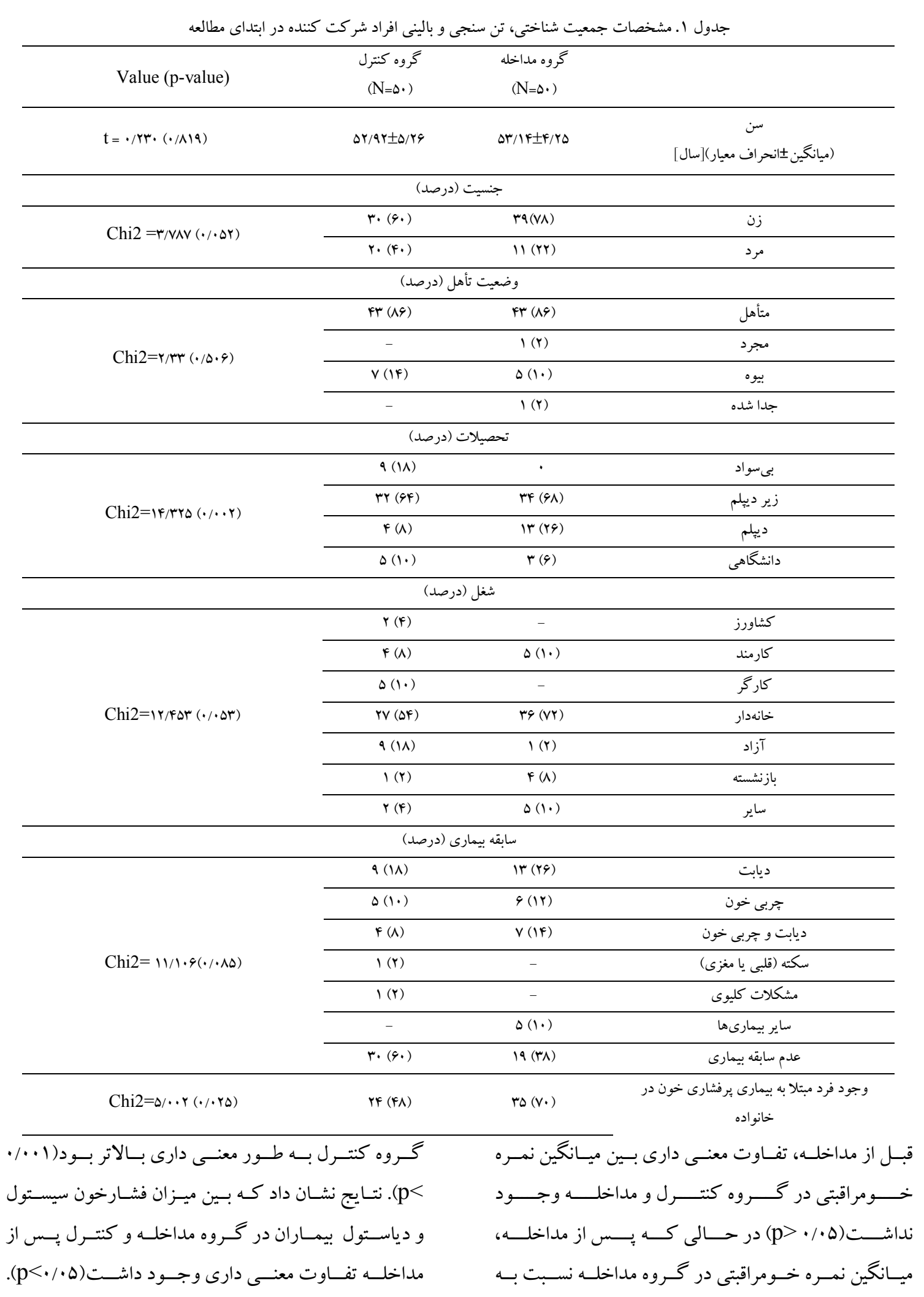


متغيرهـاى ييامـــ (نمـره خـود مراقبتى، فشـارخون سيسـتول

و دياسـتول، شــاخص نمــاى تــوده بــدنى و وزن) از سـوى

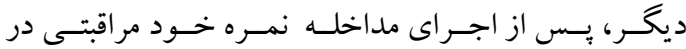

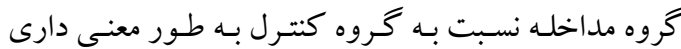

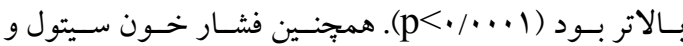

دياســتول نيـز يـسـ از مداخلــه بــه طــور معنــى دارى در

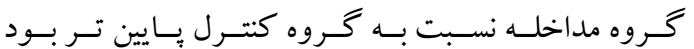

$$
\text { (جدول)( }(\mathrm{p}<\cdot \cdots \cdot)
$$

البتـه قبـل و يسـ از مداخلـهـ بــن ميـانكين وزن و شـاخص

نمايسه تـوده بــنى در كـروه مداخلـه و كنتـرل تفـاوت معنىى

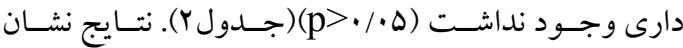

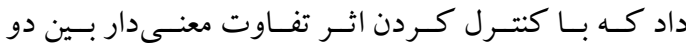

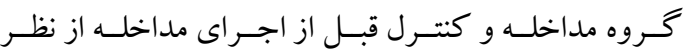

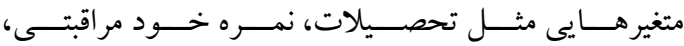
فشـارخون سيسـتول و سـابقه خـانو اد كى بيمـارى از يكسـو

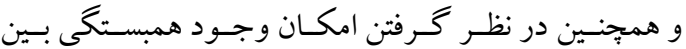

جدول r. مقايسه نمره خود مر اقبتى، فشار خون سيستول و دياستول، وزن و شاخص نماى توده بدنى در گروه مداخله و كنترل قبل و يس از مداخله

\begin{tabular}{|c|c|c|c|}
\hline Value (p-value) & كروه كنترل & كروه مداخله & \\
\hline \multicolumn{4}{|c|}{ نمره خود مر اقبتى (ميانگين \انحر اف معيار) } \\
\hline$*_{\mathrm{t}}=\cdot / \wedge \Delta \Delta(\cdot / \mathrm{rq})$ & $\Delta 1 / \Delta G \pm \Lambda / T V$ & $\Delta r / A r \pm G / T r$ & قبل از مداخله \\
\hline \multirow[t]{2}{*}{$*_{\mathrm{t}}=q /$ qqr $(<\cdot / \cdots+1)$} & $\Delta r / \Lambda \Lambda \pm V / \Lambda$. & $9 \Delta / \Delta \cdot \pm \Delta / r F$ & يس از مداخله \\
\hline & $\&_{\mathrm{t}}=-r / 4 M(<\cdot / \cdot \cdot 1)$ & $\varepsilon_{t}=-19 / \cdot \Delta \Delta(<\cdot / \cdots \cdot 1)$ & Value (p-value) \\
\hline$*_{\mathrm{t}=\| \boldsymbol{F} / \Lambda \mathrm{F}(<\cdot / \cdots \mid)}$ & $1 / H Y \cdot \pm r / 9 V$ & $|r / 9 \Lambda \pm F / N|$ & اختلاف ميانگين \\
\hline \multicolumn{4}{|c|}{ فشارخون سيستول (ميانخين \$انحر اف معيار) [ميلى متر جيوه] } \\
\hline & كروه كنترل & كروه مداخله & \\
\hline$*_{\mathrm{t}}=\operatorname{I/M\Lambda Y}(\cdot / \mathrm{TF} \cdot)$ & $\mid r N / r \cdot \cdot \pm g / \Delta r$ & $179 / 1 \cdot \pm 9 / 99$ & قبل از مداخله \\
\hline \multirow[t]{2}{*}{$* t=-Y / Y \Lambda \cdot(\cdot / \cdot Y \Delta)$} & $1+G / Y G \pm 9 / N$. & $\mid \pi r / r \cdot . \pm g / r V$ & يس از مداخله \\
\hline & ${ }_{t} t=r / \Delta V F^{\prime}(<\cdot / \cdots)$, & $\&_{t=|F / Y| Y(<\bullet / \cdots 1)}$ & Value (p-value) \\
\hline$* \mathrm{t}=\mathrm{V} / \mathrm{T})(<\cdot / \cdots 1)$ & $-1 / 94 \pm Y / 99$ & $-9 / 0 \cdot \pm r / r r$ & اختلاف ميانكين \\
\hline \multicolumn{4}{|c|}{ فشارخون دياستول (ميانگين +انحر اف معيار) [ميلى متر جيوه] } \\
\hline & كروه كنترل & كروه مداخله & \\
\hline 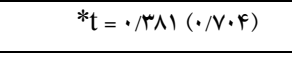 & $M / 1 \cdot \pm 9 / \cdot \Delta$ & $M / \Delta 9 \pm 9 / \cdot r$ & 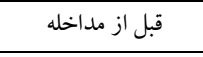 \\
\hline \multirow[t]{2}{*}{$* t=-f / \cdot \mid f(<\cdot / \cdots+1)$} & $\Lambda 9 / \Lambda \cdot \pm \Delta / \mu r$ & $\Lambda r / \Delta \Lambda \pm \Delta / 19$ & 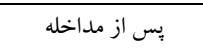 \\
\hline & $E_{\mathrm{t}}=r / r r \cdot(\cdot / \cdot r I)$ & $\&_{t=11 / r \Delta q}(<\cdot / \cdots \cdot 1)$ & Value (p-value) \\
\hline$*_{t}=\Delta / A \uparrow r(<\cdot / \cdots)$, & $-1 / r \cdot \pm F / / f$ & $-\Delta / ৭ \Lambda \pm r / N r$ & اختلاف ميانگين \\
\hline \multicolumn{4}{|c|}{ وزن(ميانگين دانحر اف معيار) [كيلو گرم] } \\
\hline$* t=\cdot / r 90(\cdot / V / 9)$ & $V V / \cdot 9 \pm I Y / \cdot V$ & $V V / a f \pm I \cdot / 9 r$ & ق قبل از مداخله \\
\hline \multirow[t]{2}{*}{$*_{\mathrm{t}}=\cdot / 1 r q(\cdot / q \cdot \cdot)$} & $v G / \Delta V \pm I I / 9 F$ & $v \& / \wedge 9 \pm 1 \cdot / \Delta \Delta$ & بس از مداخله \\
\hline & ${ }_{t}^{t}=\Delta / A V F(<\cdot / \cdots)$, & $\&_{\mathrm{t}=9 / 011(<\cdot / \cdots+1)}$ & Value (p-value) \\
\hline$* t=r / 9 V r(\cdot / \cdot r)$ & $-\cdot / \Delta Y \pm \cdot / 9 Y$ & $-1 / \cdot 1 \pm 1 / 19$ & اختلاف ميانكين \\
\hline \multicolumn{4}{|c|}{ شاخص نماى توده بدنى (ميانگين \انحر اف معيار) [ץ^(قد)/ وزن] } \\
\hline$* \mathrm{t}=\cdot / 999(\cdot / \pi \mathrm{TV})$ & $r q / V \Delta \pm r / q$. & $r \cdot / 9 \Delta \pm F / 4 r$ & 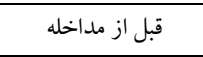 \\
\hline \multirow[t]{2}{*}{$* \mathrm{t}=\cdot / \mathrm{V} F \mathrm{~V}(\cdot / F \Delta \mathrm{V})$} & $r q / \Delta \Delta \pm r / \wedge r$ & $r \cdot / r+F / Y)$ & 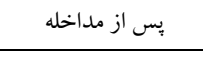 \\
\hline & $\&_{\mathrm{t}}=9 / \cdot 9 \cdot(\cdot / \cdots 1)$ & $\varepsilon_{t=9 / \Delta \Delta V(\cdot / \cdots 1)}$ & Value (p-value) \\
\hline$* t=r / \cdot \cdot q(\cdot / \cdot r r)$ & $-\cdot / r \cdot \pm \cdot / r F$ & $-\cdot / \& Y \pm \cdot / \& \Delta$ & اختلاف ميانگين \\
\hline
\end{tabular}

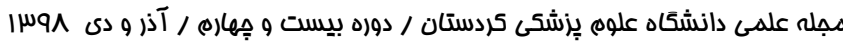


جدول ـ مقايسه نمره خود مراقبتى، فشار خون سيستول و دياستول، وزن و شاخص نماى توده بدنى بين دو گروه مداخله و كنترل با كنترل اثرات مخدوش كند

\begin{tabular}{|c|c|c|c|}
\hline \multirow{2}{*}{$(p-$-value $) *$} & \multicolumn{2}{|c|}{ ميانخين (هذ٪ فاصله اطمينان) } & \multirow{2}{*}{ متغير } \\
\hline & كروه كنترل & كروه مداخله & \\
\hline $\begin{array}{l}\mathrm{F}=61 / 26 \\
\mathrm{P}<\bullet / \cdots 1\end{array}$ & $\Delta r / M \Lambda(\Delta \cdot / 99-\Delta \Delta / \cdot 9)$ & $94 / \cdot 1(9 \cdot / 0 \cdot-99 / 99)$ & 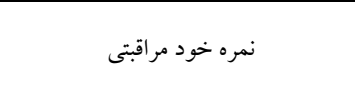 \\
\hline $\begin{array}{l}\mathrm{F}=11 \mathrm{~V} / 49 \\
\mathrm{P}<\cdot / \cdots+1\end{array}$ & $\mid r G / Y q(\mid r F / r q-1 \Gamma N / 19)$ & $\mid r r / r \cdot(|r| / \Delta|-| r \Delta / \cdot \Lambda)$ & فشارخون سيستول [ميلى متر جيوه] \\
\hline $\begin{array}{l}\mathrm{F}=\Delta F / q \vee \\
\mathrm{p}<\bullet / \cdots)\end{array}$ & $\Lambda \varepsilon / \Lambda \cdot(\Lambda \Delta / \Upsilon \Lambda-\Lambda \Lambda / \sim I)$ & $\Lambda r / \Delta \Lambda(\Lambda I / 1 \cdot-\Lambda F / \Delta)$ & فشارخون دياستول [ميلى متر جيوه] \\
\hline $\begin{array}{l}\mathrm{F}=\cdot / \cdot r F \\
\mathrm{P}=\cdot / A V V\end{array}$ & $r Q / \Delta \Delta(Y N / I V-r \cdot / Q Y)$ & $r \cdot / r \mu(Y q / \cdot 1-r \mid / 4 q)$ & شاخص نماى توده بدنى [ץ^(قد)/وزن] \\
\hline $\begin{array}{l}\mathrm{F}=\cdot \cdot / \cdot \cdot \\
\mathrm{P}=\cdot / \text { १/ }\end{array}$ & $\vee 9 / 99(V / / 1 \Lambda-V Q / 9 \vee)$ & 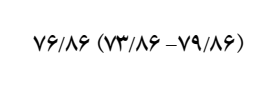 & 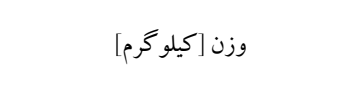 \\
\hline
\end{tabular}

قُ تأثير تفاوت معنى دار بين دو گروه مداخله و كنترل قبل از اجراى مداخله از نظر متغيرهايى مثل تحصيلات، نمره خود مراقبتى، فشارخون سيستول و سابقه

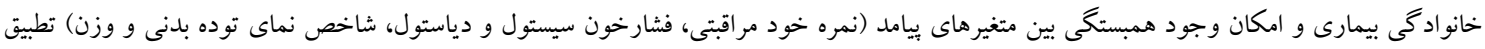

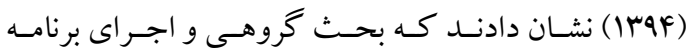
خـود مر اقبتى و رفتارهـاى بهداشـى در كنتـرل فشـارخون

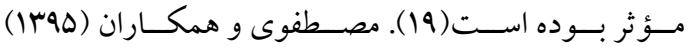

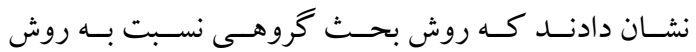

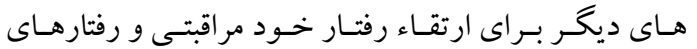
بهداشـتى تـأثير قابـل تـوجهى داشـته اسـت (Y). همجنسين

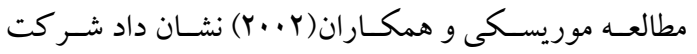

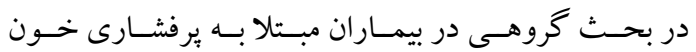
نقش مهمسى در كنتـرل فشـار خـون افـراد مبـتلا دارد(Y).

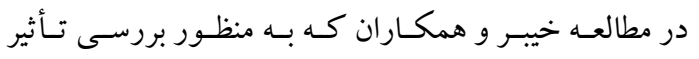

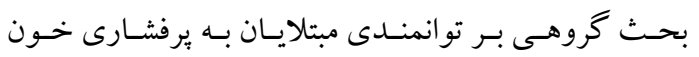

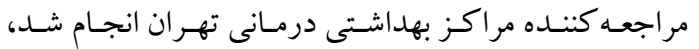

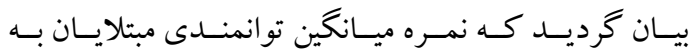

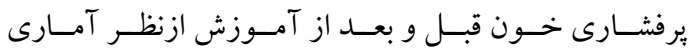

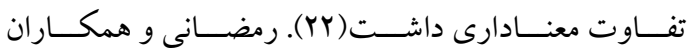

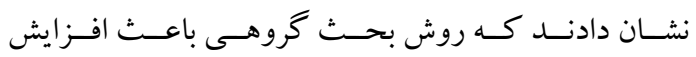
نتايج نشـان داد كـه آموزش در غالب بحـث گروهـى در

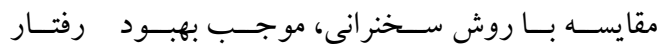
خـودمر اقبتى بيمـاران و در نتيجهـ كـاهش معنى دار فشـار خـون سيسـتول و دياسـتول آنهـا مسى شـود. طبـق نتـايج

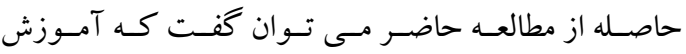

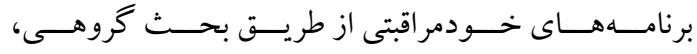
عملكرد مبتلايـان بـه برفشـارى خـون فشـار را بـه طور قابـل ملاحظهاى ارتقا مىدهد.

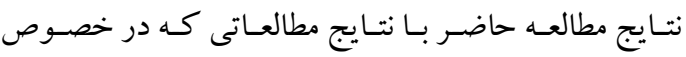
تأثير آمـوزش بـر بهبـود رفتـار خـود مر اقبتى بيمـاران مبتلا بــه برفشـارى خــون انجــام شـــده اسـت، همخــوانى دارد.

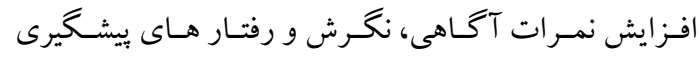
كنــــه از فشـار خـون بــالا در زنــان بــاردار در مطالعـهـ

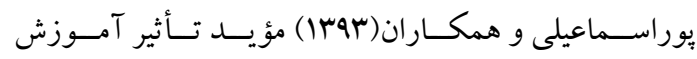

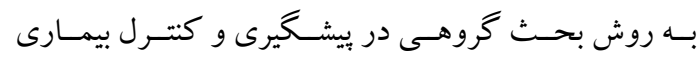

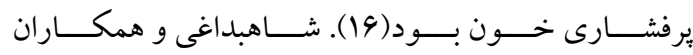


نفـس و يــروش روحيـهـ انتقــــى، تقويـت قـوه اسـتـلال و

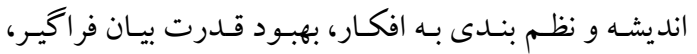

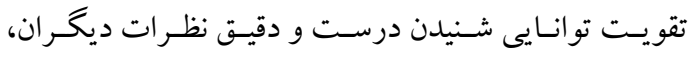

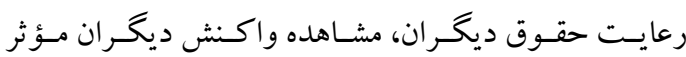

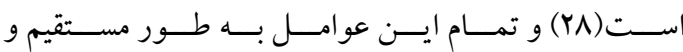

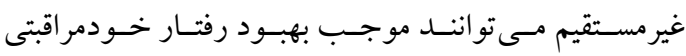

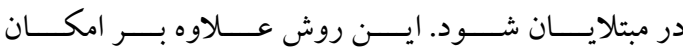

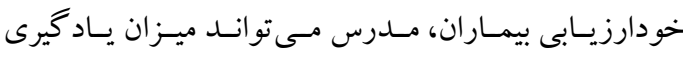

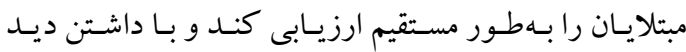
عميـق تـر نسـبت بـه احتياجـات آنهـا، آمـوزش را برنامـهـ

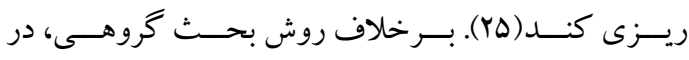

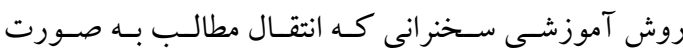

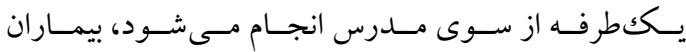

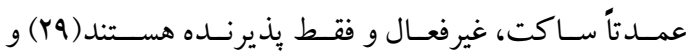

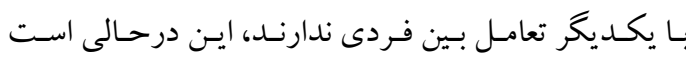
كـه بحـث و تبـادل نظـر بـين مبتلايـان بـه برفشـارى خـون و انتقـال تجـارب مسى توانــ تـأثير بسز ايى در يـادگيرى رفتـار

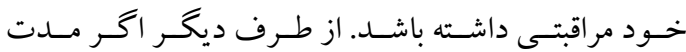

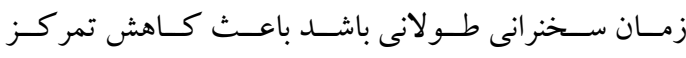

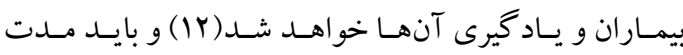
زمـان آن را كـاهش داد؛ ايـن در حسالى اسـت كـه آمـوزش

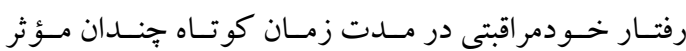

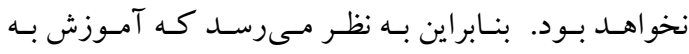
شـيوه بحــث گروهـى و مشــار كت دادن بيمــاران در امـر

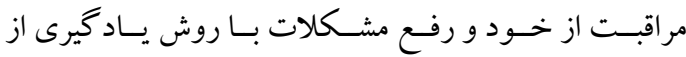

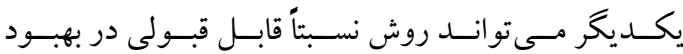

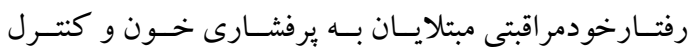

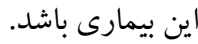

يكـى از محسـدوديتهــاى مطالعـه حاضــر عـــم بررسىى

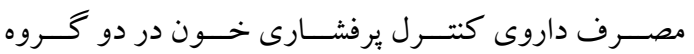

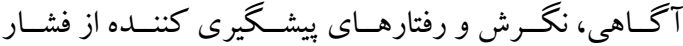

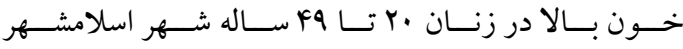
شـــ(19). نتـايج مطالعهـ حاضـر بـا مطالعـات در كشـورهاى

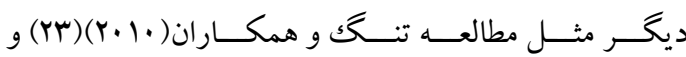
مطالعه لى و همكاران (Y.19) (YF) همسو است.

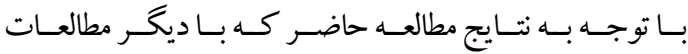

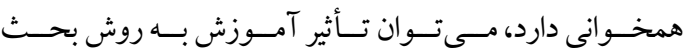

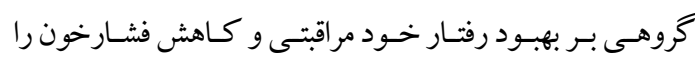

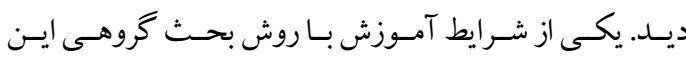

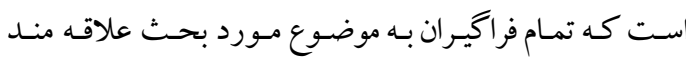

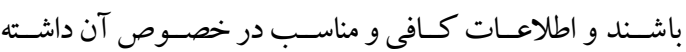

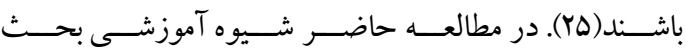

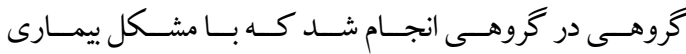

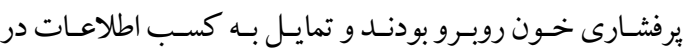

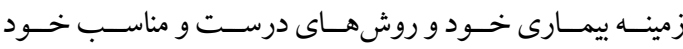

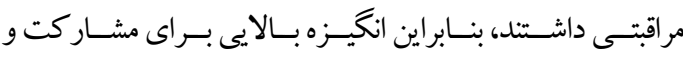

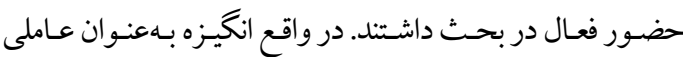

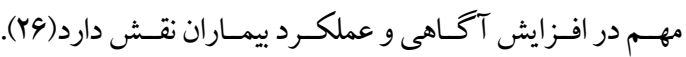

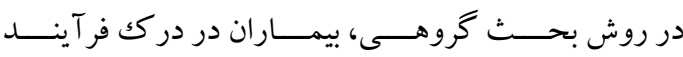

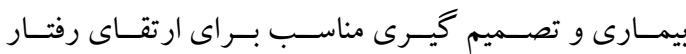
خودمر اقبتى به يكديخر كمك مى كنند (YV).

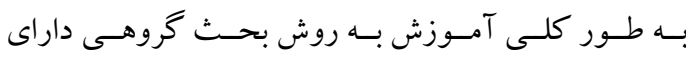

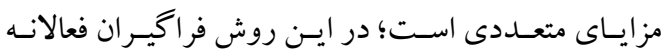
در امـر يـادگيرى مشـار كت دارندـ و مسؤوليت يـادگيرى خهود را بـهـ عهـده مسى گيرنســ. بـه فراخيــران فرصـت داده

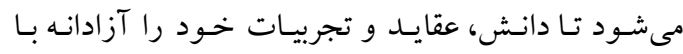

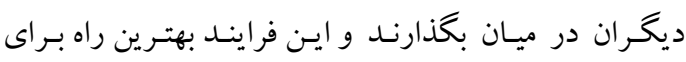
تغييـر نخــرش نسبت بـه بيمـارى و رفتارهـاى خـود مراقبتى

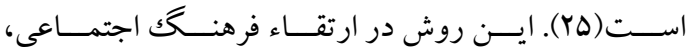

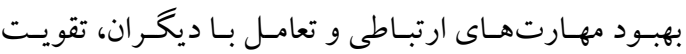

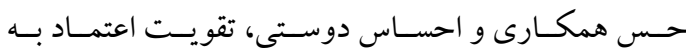




\section{نتيجه كيرى}

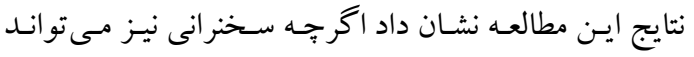

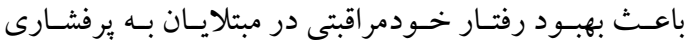

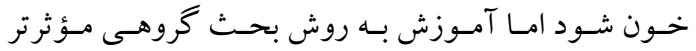

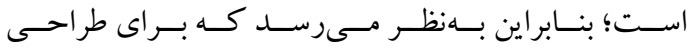

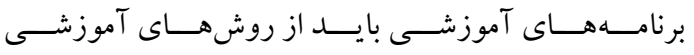

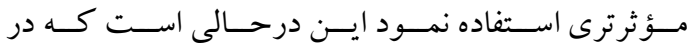

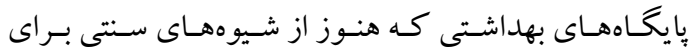

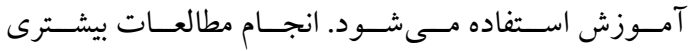

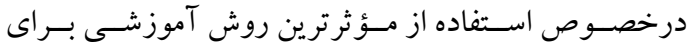

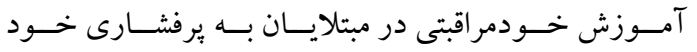

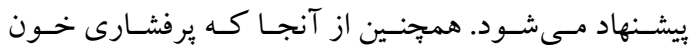

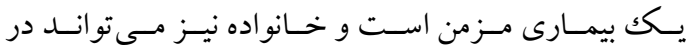

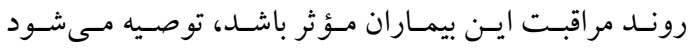

"ـرزوهشهــاى در خصـوص آمـوزش بـهـ خـانو اده مبتلايـان

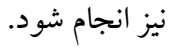

تشكر و قدردانى

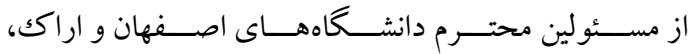

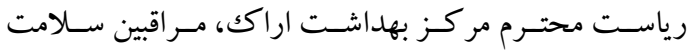

يا يايخـاههـاى دخيـل در طـرح تمـامى بيمـارانى كـه مـا را در

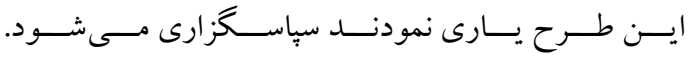

$$
\begin{aligned}
& \text { كنتـرل و مداخلـه بـود، در حسالى كـه ممكـن اسـت بخشـى } \\
& \text { از اختـلاف مشـاهده شـــه بـين دو گَروه بـه دليـل مصـرف }
\end{aligned}
$$

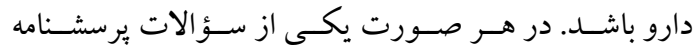

$$
\begin{aligned}
& \text { رفتـار خـود مراقبتسى در خصـوص فراموشى مصـرف دارو } \\
& \text { اسـت كـهـ تـا حسـدودى ايـن محسدوديت مطالعهـ را جبـران }
\end{aligned}
$$

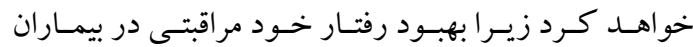

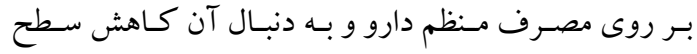

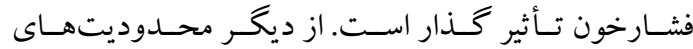

$$
\begin{aligned}
& \text { مطالعـه ســطح يـايين اجتمــاعى -اقتصــادى و تحصـيلات }
\end{aligned}
$$

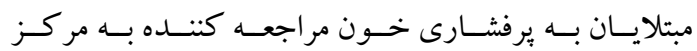

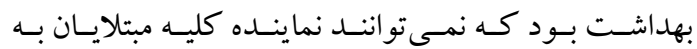

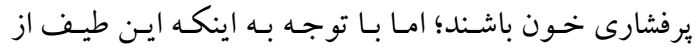

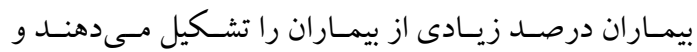

$$
\begin{aligned}
& \text { نياز بيشترى بـه مراقبـت و آمـوزش دارنـد، بـه نظر مسىرســ }
\end{aligned}
$$

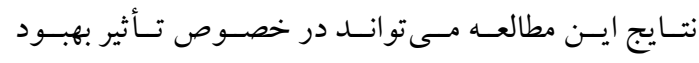

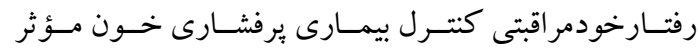

$$
\begin{aligned}
& \text { باشـــ از طرفى محسدود بـودن مطالعه بـهـ مبتلايـان سـاكن }
\end{aligned}
$$

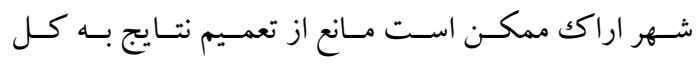

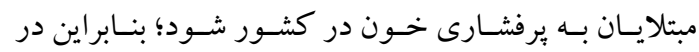

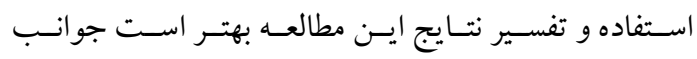

$$
\begin{aligned}
& \text { احتياط رعايت گردد. }
\end{aligned}
$$

\section{References}

1.Levy PD, Cline D. Asymptomatic hypertension in the emergency department: a matter of critical public health importance. Academic Emergency Medicine. 2009;16(11):12517.PMID: 19845553

2.James PA, Oparil S, Carter BL, Cushman WC, Dennison-Himmelfarb C ,Handler J, et al. evidence-based guideline for the management of high blood pressure in adults: report from the panel members appointed to the Eighth Joint National Committee (JNC 8). JAMA. 2014;311(5):507-20.

3.Wang Y, Wang Q.J. The prevalence of prehypertension and hypertension among US adults according to the new joint national committee guidelines: new challenges of the old problem. Arch Intern Med. 2004;164(19):2126-34.PMID: 15505126

4.Jafari Oori Mehdi, Mohammadi Farahnaz, Norozi Kian, Fallahi-Khoshknab Masoud, Ebadi Abbas, Ghanei Gheshlagh Reza Prevalence of HTN in Iran: Meta-analysis of Published Studies in 2004-2018 Current Hypertension Reviews. 2019;15: 113-22.

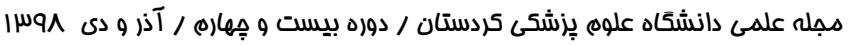


5.CDC. Operational Program for the Prevention and Control of Heart Disease and Hypertension,. Arak University of Medical Sciences,. 2018.

6.Wilcox S, Sharkey J, Mathews A, Laditka JN, Laditka SB, Logsdon RG, et al. Perceptions and beliefs about the role of physical activity and nutrition on brain health in older adults. The Gerontologist. 2009;49(S1):S61-S71.PMID: 19525218

7.Eshah NF, Al-daken LI. Assessing publics' knowledge about hypertension in a communitydwelling sample. Journal of Cardiovascular Nursing. 2016;31(2):158-65. PMID: 25658184

8.Han HR, Lee H, Commodore-Mensah Y, Kim M. Development and validation of the hypertension self-care profile: a practical tool to measure hypertension self-care. The Journal of cardiovascular nursing. 2014;29(3):11-3.PMID: 24088621

9.Hosseini F, Farshidi H, Aghamolaei T, Madani A, Ghanbarnejad A. The Impact of an Educational Intervention Based On PRECEDE - PROCEED Model on Lifestyle Changes among Hypertension Patients. Journal of Health Education and Health Promotion. 2014;2(1):17-27.

10.Bairami Sh, Fathi Y, Mohammadinasab S, Barati M,Mohammadi Y. Relationship between Self-care Behaviors and Quality of Life among Hypertensive Patients Visiting Comprehensive Health Centers in Hamadan, Iran. J Educ Community Health. 2017;4(1):20-7. 11.Safavi M, Samadi N, Mahmoodi M. The relationship between self-concept and quality of life in patients with type 2 diabetes. Medical Science Journal of Islamic Azad UnivesityTehran Medical Branch. 2013;23(2):148-53.

12.Fatahi Bafghi A, Karimi H, Anvari MH, Barzegar K. Comparison of Lacture and Group Discussion on Learning Rate among Laboratory Science Students. Strid Dev Med Educ. 2007;4(1):51-6.PMID: 25512938.

13.Saberi Javad, Javaheri Javad, Mashayekhi Nadia, Mohsen nezhad Azita, Dard Sheikh Torkamani Fazileh, Yadegari Nasrin, et al. Tips for prevention and control of blood pressure. Arak, Markazi, Iran.: Arak University of Medical Sciences, ; 2015.

14.Andereck KL. Evaluation of a tourist brochure. Journal of Travel \& Tourism Marketing. 2005;18(2):1-3.

15.Ke L, Mason RS, Mpofu E, Vingren J, Li Y, Graubard Bl, et al. Hypertension and other cardiovascular risk factors are associated with vitamin D deficiency in an urban Chinese population: A short report. The Journal of steroid biochemistry and molecular biology. 2017; 173:286-91.PMID: 27865973.

16.Ramezankhani A, Pooresmaeili A, Khodakarim S. the effect of education on knowledge , attitude and preventive behaviors of high blood pressure based on group discussion in women 20-49 years old, Islamshahr city. Razi journal of medical sciences 2017;24(1559.- $)$ :(

17.Izadirad H, Niknami Sh, Zareban I, Tavousi M. Health literacy and prenatal care adequacy index on the outcome of birth weight in pregnant women in Balochistan, Iran. Journal of the Iranian Institute for Health Sciences Research. 2018;17(2):191-8.

18.Rouzbahani F, Sheykhtaheri A, Farzandipour M, Rangraz Jeddi F, Mobarak Ghamsari Z. Evaluation of Training Educators Performance from Points of Views of Medical Record Students in Kashan University of Medical Sciences, Iran. Journal of Health Information Management. 2011;8(2):251-7.

19.Shahbodaghi Z, Borhani F, Rayani M. the effects of self-care program on blood pressure of patients with diabets. Medical-Surgical Nursing Journal 2014;3(3):163-9.

20.Sima peyman T, Pirzadeh A, Hasanzadeh A, Mostafavi F. Self-care behaviors and its relationship with health literacy in hypertensive patients in Isfahan city Journal of Health system Research, . 2017;13(3):381-7.

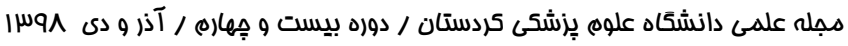


21.Morisky DE, Lees NB, Sharif BA, Liu KY, Ward HJ. Reducing disparities in hypertension control: a community-based hypertension control project (CHIP) for an ethnically diverse population. Health Promotion Practice. 2002;3(2):264-75.

22.Kheibar N, Nik-Pour S, Haji-Kazemi E, Haghani H, Dastoorpour M. Investigation of the effects of group discussion on the empowerment of patients with hypertension who were referred to two health centersin Tehran in 1390. Hakim Jorjani J. 2015;2(1):33-9.

23.Tang TS, Funnell MM, Brown MB, Kurlander JE. Self-management support in "realworld" settings: an empowerment-based intervention. Patient Educ Couns. 2010;79(2):17884.PMID: 19889508.

24.Lee KS, Moser DK, Dracup K. Relationship between self-care and comprehensive understanding of heart failure and its signs and symptoms. Eur $\mathrm{J}$ Cardiovasc Nurs. 2018;17(6):49.0. - - TPMID: 29192794

25.Malakouti M. Teaching in small groups (Group discussion). Magazine Training strategies. 2010;2(4):183-7.

26.Terry Page G, Thomas J.B, Marshall A.R. International Dictionary of Education, , 1979:326. London and Worcester, Billing and sons Ltd,: The MIT Press; 1st MIT Press Pbk. Ed edition (February 19, 1980); 1980.

27.Ahmadi Z, Sadeghi M, Tabandeh A, Laripoor L, Khademi H. A comparative study on the effect of self care care behaviors by health care providers and peers on glycosylated hemoglobin in patients with diabetes. Iranian Journal of Endocrine and Metabolism. Twomonth Journal of Endocrinology and Metabolism Research Center. 2017;19(3):144-50.

28.Heravi M, Jadid Milani M, Rejeh N. Effectiveness of Lecture and Focus GroupTeaching Methods on Nursing Students Learning in Community Health Course. IJME. 2004;4(1):55-60 [Full Text in Persian.[

29.Bafekri Kh, Taghavi T, Seyedfatemi N, Movaghari M. The Effects of Group DiscussionBased Education on Coping Skills in Stressful Situations among High Schools Students. Iranian Journal of Nursing Research. 2017;12(2 (47):S(1-7). 